\title{
Titration of serum CEA, p53 antibodies and CEA-IgM complexes in patients with colorectal cancer
}

\author{
TAIKI KOJIMA ${ }^{1}$, KAZUHIRO YOSHIKAWA ${ }^{2}$, TAKANORI MATSUI ${ }^{1}$, \\ YASUHIRO KODERA ${ }^{3}$ and HIROSHI KOJIMA ${ }^{1}$
${ }^{1}$ Department of Gastroenterological Surgery, Aichi Cancer Center, Aichi Hospital, Kuriyado 18, Kakemachi, Okazaki-shi, Aichi-ken 444-0011; ${ }^{2}$ Promoting Center for Clinical Research, Aichi Medical University;
${ }^{3}$ Department of Surgery II, Nagoya University Graduate School of Medicine, Aichi, Japan

Received November 25, 2008; Accepted February 13, 2009

DOI: $10.3892 / \mathrm{mmr} 00000124$

\begin{abstract}
The early detection of colorectal cancer is key to the improvement of patient survival. Although fecal occult blood testing and carcinoembryonic antigen (CEA) in serum are widely used as non-invasive screening methods, they have limited sensitivity. Forty-five patients who underwent surgery for primary colorectal cancer were enrolled in this study. Sixteen $(36 \%)$ were determined to have Stage I tumors, 15 (33\%) Stage II tumors and 14 (31\%) Stage III tumors. Serum samples from a non-colorectal cancer group of 22 patients with no tumors were analyzed as a control. In each serum sample, CEA, p53 antibodies and CEA-IgM complexes were measured. The combination of these three tests had an overall sensitivity of $53 \%(24 / 45)$, and revealed $31 \%(5 / 16)$ of the tumors to be in Stage I, 53\% (8/15) to be in Stage II and $79 \%(11 / 14)$ to be in Stage III, while the false positive rate was $18 \%$ (4/22). The combined use of these three tests in serum is potentially an effective screening method for the detection of colorectal cancer, at even the early stages of the disease.
\end{abstract}

\section{Introduction}

Colorectal cancer is the third most commonly diagnosed type of cancer, and represents approximately $11 \%$ of all new cancer cases (1). Patient survival depends to a large extent on the stage of disease at diagnosis. In patients with localized disease, the 5-year survival rate is approximately $90 \%$, whereas in patients with regional spread this decreases to approximately $60 \%$. In patients with distant metastases, the 5-year survival rate is less than $10 \%(2)$.

A number of screening tests are available for the early detection of colorectal cancer. These include digital rectal

Correspondence to: Dr Taiki Kojima, Department of Gastroenterological Surgery, Aichi Cancer Center, Aichi Hospital, Kuriyado 18, Kakemachi, Okazaki-shi, Aichi-ken 444-0011, Japan

E-mail: tkojima@acc-aichi.com

Key words: colorectal cancer, tumor marker, CEA, p53 antibodies, CEA-IgM complexes examination, fecal occult blood testing, barium enema examination, colonoscopy and, most recently, computed tomographic colonography. A reduction in colorectal cancer mortality can be achieved through the detection and treatment of the disease at its early stages, but the current diagnostic methods need to be improved in terms of their sensitivity, specifity, invasiveness and cost $(3,4)$. Colonoscopy is an effective screening test, but has been met with limited public acceptance due to its invasiveness and cost. Since the measurement of tumor markers in serum, urine and feces is noninvasive, the use of these markers is expected to be more widely accepted for the screening of early-stage colorectal cancer.

Although fecal occult blood testing is widely used as a non-invasive screening method, it has a limited sensitivity of approximately $20 \%(5,6)$, though its specifity is approximately $95 \%$. Carcinoembryonic antigen (CEA) in serum is also widely used. CEA was found to be elevated in up to $19 \%$ of smokers and $3 \%$ of a healthy control population (7), demonstrating an overall sensitivity of $30-40 \%$ in discriminating healthy individuals from cancer patients. However, this sensitivity was dramatically diminished during the early stages of cancer, decreasing to less than $10 \%$ in Dukes' stage A colorectal cancer. Since CEA is elevated in the advanced stages of incurable cancer but low during the early curable stages, its potential to positively affect patient survival is limited.

New types of serum markers have been reported to be capable of overcoming these limitations in detecting early stage colorectal cancer (8). One such example is serum p53 antbodies. The tumor suppressor p53 gene, located on chromosome $17 \mathrm{p} 13.1$, frequently undergoes mutation in the genesis of human cancer (9), with a reported mutation frequency of at least $50 \%$. This leads to the synthesis of a mutant protein with a longer than normal half life, and to the massive overexpression of the products of the protein. The accumulation of mutant $\mathrm{p} 53$ protein has been found to be immunogenic in cancer patients, and results in the production of p53 antibodies (10). The sensitivity acheived when screening for p53 antibodies in colorectal cancer is $24 \%$, and is higher during the early stages than the advanced stages of the disease (8).

The other type of commonly used new tumor marker is CEA-IgM complexes (11). Although the presence and ele- 


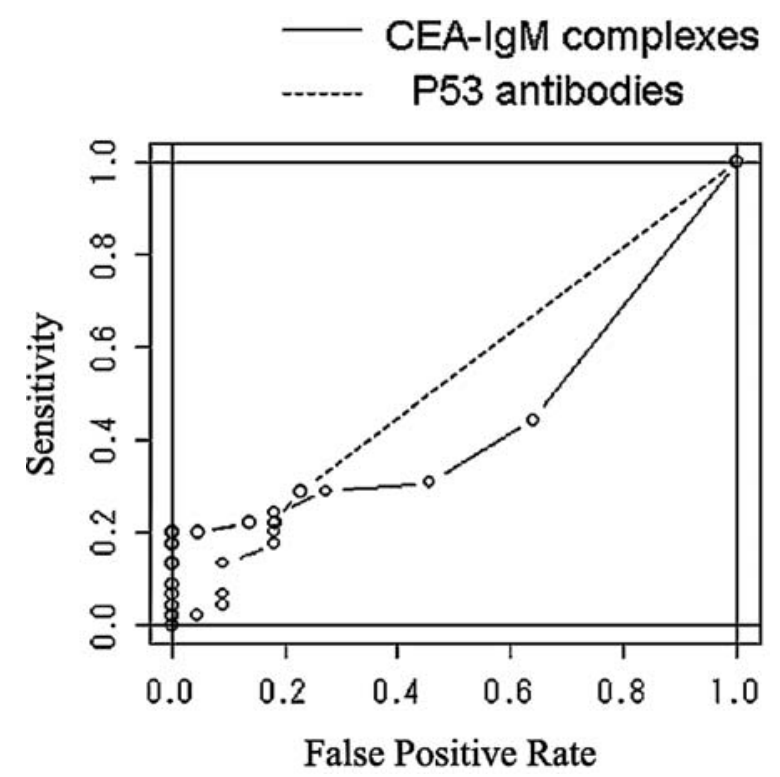

Figure 1. ROC curves comparing the distribution of the serum levels of p53 antibodies and CEA-IgM complexes in patients with colorectal cancer $(n=45)$ vs. the control group $(n=22)$.

vation of CEA-containing complexes in the serum of cancer patients have been established (12), CEA-IgM complexes have an improved sensitivity (13), with an overall sensitivity of $38 \%$ and a sensitivity of $29 \%$ during the early stages of the disease, without compromising the specifity of detection (11).

In this report, we combined screening for CEA, p53 antibodies and CEA-IgM complexes in serum in order to achieve improved sensitivity in detecting the early stages of colorectal cancer.

\section{Patients and methods}

Patients. Forty-five patients who underwent surgery for primary colorectal cancer at the Department of Gastroenterological Surgery of Aichi Cancer Center (Aichi Hospital, Japan) between December 2005 and May 2007 were enrolled. Patients who did not undergo surgery were excluded. Written informed consent was obtained from each patient. No patients had received pre-operative radiotherapy or chemotherapy. There were $26(58 \%)$ male and $19(42 \%)$ female patients, with an mean age of 58.5 years (range $42-85$ ). Tumors were located in the colon in 27 cases $(60 \%)$ and in the rectum in 18 cases $(40 \%)$. Tumor staging was performed according to the International Tumor-Node-Metastasis (TNM) staging guidelines, and histological grade was assessed according to the World Health Organization (WHO) criteria. Sixteen of the tumors $(36 \%)$ were determined to be of Stage I, $15(33 \%)$ of Stage II, 14 (31\%) of Stage III, and none of Stage IV. Thirtythree tumors $(73 \%)$ were well-differentiated, 12 (27\%) were moderately differentiated, and none were poorly differentiated.

Serum samples were obtained from 22 individuals who underwent gastric endoscopy. Those found to have no tumors were assigned to a non-colorectal cancer group, and their samples were analyzed as the control. Written informed consent was obtained from each subject. Subjects comprised $14(64 \%)$ male and $8(36 \%)$ female individuals, with an mean age of 55.5 years (range $36-82$ ).
Serum samples. The serum samples were collected at the Aichi Cancer Center, Aichi Hospital, from 45 patients suffering from colorectal cancer and from 22 non-colorectal cancer (control) patients prior to respective surgery or gastric endoscopy. The samples were stored at $-80^{\circ} \mathrm{C}$ until time of assay.

Enzyme immunoassay for serum p53 antibodies. Serum p53 antibody levels were assessed using the anti-p53 EIA kit II (Mesacup anti-p53 test; Medical and Biological Laboratories, Nagoya, Japan). In brief, after $1 \mathrm{~h}$ at room temperature, the samples were added to microtiter wells coated with wildtype human p53 or a control protein to detect non-specific interactions. After washing, a peroxidase-conjugated goat anti-human IgG that binds p53 antibodies was applied for $1 \mathrm{~h}$ at room temperature, then a substrate solution was added for $30 \mathrm{~min}$ at room temperature. After the addition of stop solution, color development was assessed by measuring absorption at $450 \mathrm{~nm}$ using a photospectrometer. p53 antibody levels were determined from a calibration curve constructed from the specific signals of the reference standard. The cut-off value for serum p53 antibodies was determined to be $6.0 \mathrm{U} / \mathrm{ml}$ based on ROC curve anaysis.

Enzyme immunoassay for serum CEA-IgM complexes. The levels of serum CEA-IgM complexes were assessed by the colon-IC ELISA kit (Xeptagen, Pozzuoli, Italy). In brief, in 96-well ELISA plates coated with anti-human CEA antibody, $100 \mu 1$ of serially diluted reference standard or serum samples in dilution buffer were incubated for $1 \mathrm{~h}$ at room temperature. After washing, the CEA-IgM complexes were incubated with enzyme-conjugated anti-human $\operatorname{IgM}$ for $1 \mathrm{~h}$ at room temperature, then developed and assessed by measuring absorption at $405 \mathrm{~nm}$ using an ELISA plate reader. Levels of CEA-IgM complexes were determined from a calibration curve constructed from the reference standard. The cut-off value was determined to be $45 \mathrm{AU} / \mathrm{ml}$ based on ROC curve anaysis.

CEA assay. Serum CEA concentrations were measured with Chemiluminescent Immunoassay, using ARCHITECT CEA (Abbott Japan, Tokyo, Japan). The cut-off value of CEA was $5 \mathrm{ng} / \mathrm{ml}$, in accordance with the manufacturer's instructions.

Statistical analysis. The results of the assays for CEA, p53 antibodies and CEA-IgM complexes were analyzed in parallel. The areas under the ROC curve were calculated using Software R (14) .

\section{Results}

The results of the ROC curve analysis of p53 antibodies and CEA-IgM complexes are plotted in Fig. 1. The diagnostic accuracy, represented as the areas under the ROC curve, indicates that p53 antibodies are superior to CEA-IgM complexes (value, 0.548 vs. 0.427 ).

The individual sensitivities of the three tests are summarized in Table I, divided according to the overall number of colorectal cancer patients, patients in Stages I, II, III, and non-colorectal cancer (control) patients. 
Table I. Sensitivity of testing for CEA, p53 antibodies and CEA-IgM in serum.

\begin{tabular}{lccccc}
\hline & \multicolumn{5}{c}{ Colorectal cancer patients } \\
\cline { 2 - 5 } & $\begin{array}{c}\text { Overall }(\mathrm{n}=45) \\
\text { No. }(\%)\end{array}$ & $\begin{array}{c}\text { Stage I }(\mathrm{n}=16) \\
\text { No. }(\%)\end{array}$ & $\begin{array}{c}\text { Stage II }(\mathrm{n}=15) \\
\text { No. }(\%)\end{array}$ & $\begin{array}{c}\text { Stage III }(\mathrm{n}=14) \\
\text { No. }(\%)\end{array}$ & $\begin{array}{c}\text { Control }(\mathrm{n}=22) \\
\text { No. }(\%)\end{array}$ \\
\hline $\begin{array}{l}\text { CEA-positive } \\
\text { p53 antibodies-positive }\end{array}$ & $9(20)$ & $1(6)$ & $1(7)$ & $7(50)$ & $0(0)$ \\
$\begin{array}{l}\text { CEA-IgM complexes- } \\
\text { positive }\end{array}$ & $9(20)$ & $2(13)$ & $2(13)$ & $5(36)$ & $4(29)$ \\
\hline
\end{tabular}

Cut-off value: CEA, $5 \mathrm{ng} / \mathrm{ml}$; p53 antibodies, $6 \mathrm{U} / \mathrm{ml}$; CEA-IgM complexes, 45 AU/ml.

Table II. Combined sensitivity of testing for CEA, p53 antibodies and CEA-IgM in serum.

\begin{tabular}{lcccc}
\hline & \multicolumn{4}{c}{ Colorectal cancer patients } \\
\cline { 2 - 5 } & $\begin{array}{c}\text { Overall }(\mathrm{n}=45) \\
\text { No. }(\%)\end{array}$ & $\begin{array}{c}\text { Stage I }(\mathrm{n}=16) \\
\text { No. }(\%)\end{array}$ & $\begin{array}{c}\text { Stage II }(\mathrm{n}=15) \\
\text { No. }(\%)\end{array}$ & $\begin{array}{c}\text { Stage III }(\mathrm{n}=14) \\
\text { No. }(\%)\end{array}$ \\
\hline $\begin{array}{l}\text { CEA + p53 antibodies- } \\
\text { positive }\end{array}$ & $15(33)$ & $2(13)$ & $3(20)$ & $10(71)$ \\
$\begin{array}{l}\text { CEA + CEA-IgM } \\
\text { complex-positive }\end{array}$ & $21(47)$ & $5(31)$ & $6(40)$ & $10(71)$ \\
$\begin{array}{l}\text { CEA-IgM + p53 } \\
\text { antibodies-positive }\end{array}$ & $13(29)$ & $5(31)$ & $7(47)$ & $7(50)$ \\
$\begin{array}{l}\text { CEA + p53 antibodies }+ \\
\text { CEA-IgM complexes- } \\
\text { positive }\end{array}$ & $24(53)$ & $5(31)$ & $8(53)$ & $11(79)$ \\
\hline
\end{tabular}

Cut-off value: CEA, 5 ng/ml; p53 antibodies, $6 \mathrm{U} / \mathrm{ml}$; CEA-IgM complexes, 45 AU/ml.

Table III. Overlapping positive results of CEA, p53 antibodies and CEA-IgM testing in serum samples*.

\begin{tabular}{lccc}
\hline & $\begin{array}{c}\text { Also } \\
\text { CEA-positive }\end{array}$ & $\begin{array}{c}\text { Also p53 } \\
\text { antibodies-positive }\end{array}$ & $\begin{array}{c}\text { Also CEA-IgM } \\
\text { complexes-positive }\end{array}$ \\
\hline $\begin{array}{l}\text { CEA-positive }(n=9) \\
\text { p53 antibodies- }\end{array}$ & - & 3 & 1 \\
positive $(n=9)$ & 3 & - & 3 \\
$\begin{array}{l}\text { CEA-IgM complexes- } \\
\text { positive }(n=13)\end{array}$ & 1 & 3 & - \\
\hline
\end{tabular}

*Out of the total 24 samples that tested positive for all three markers among 45 overall colorectal cancer and 22 control serum samples.

Table II shows the sensitivity as determined by the three tests combined. The best diagnostic sensitivity was obtained by the combination of all three tests. Sensitivity in the overall number of colorectal cancer patients was $53 \%(24 / 45)$; in Stage I, 31\% (5/16); in Stage II, 53\% (8/15); and in Stage III, $79 \%(11 / 14)$. The false positive rate was $18 \%(4 / 22)$.
When the three tests were combined, the indices of diagnostic sensitivity were increased. The overlapping of positive results for colorectal cancer based on CEA, p53 antibodies and CEA-IgM complexes testing are summarized in Table III. Minimal overlapping of the positive results of the three markers was observed. 


\section{Discussion}

Recent advances in biotechnology, such as the fecal DNA panel (5) or SELDI-TOF-MS $(15,16)$, have made various approaches to detecting new biomarkers possible.

In this study, we selected the commonly used molecular markers, CEA, p53 antibodies and CEA-IgM complexes. Inspired by the combination of known tumor markers with various cytokines (17), we hypothesized that different tumor markers may have minimal overlapping results, and thus result in a higher sensitivity in colorectal cancer detection.

p53 antibodies have been approved by the Ministry of Health, Labour and Welfare in Japan as tumor markers for esophageal, breast and colorectal cancer. In our study, the sensitivity of p53 antibodies in detecting colorectal cancer was $20 \%$, slightly less than that previously reported $(24 \%)$ (8). This may be due to differences in study population, such as the stage distribution of tumors or the number of patients.

To the best of our knowledge, this is the first Japanese study to test for CEA-IgM complexes, which were described by Castaldi et al (11). According to the results of our ROC analysis, CEA-IgM complexes had a lower sensitivity for detecting colorectal cancer than p53 antibodies. The sensitivity of CEA-IgM complexes in this study was found to be $29 \%$, less than that previously reported $(38 \%)$. In addition, the false positive rate in this study was $18 \%$, higher than that previously reported (5\%). These differences may be attributed to differences in the ethnic backgrounds of the populations. Further studies are needed to evaluate the efficacy of CEA-IgM complexes for detecting colorectal cancer in patients of Japanese origin.

CEA has previously been demonstrated to exhibit a high sensitivity as a marker for detecting advanced colorectal cancer (7),. In the present study, CEA detected $50 \%$ of Stage III colorectal cancers, more than those deteced by p53 antibodies $(36 \%)$ or CEA-IgM complexes $(29 \%)$.

While CEA alone is minimally effective at detecting the early stages of colorectal cancer (in this study: Stage I, 6\% and Stage II, 7\%), by combining p53 antibodies and CEAIgM complexes, $31 \%$ of Stage I, 53\% of Stage II and $79 \%$ of Stage III tumors were detected in our study, $53 \%$ in the overall colorectal cancer sample. Although the characteristics of the patients in the present study are not the same as those in previous reports, the results indicate that a combination of the three serum tumor markers provides higher sensitivity than fecal occult blood testing, which is currently widely used as a non-invasive screening method $(5,6)$.

Based on these results, we plan in future to conduct multiinstitutional tests in Japan using a larger population sample.

\section{Acknowledgements}

This study was supported by the Aichi Cancer Research Foundation.

\section{References}

1. Jemal A, Tiwari RC, Murray T, Ghafoor A, Samuels A, Ward E, Feuer EJ and Thun MJ: Cancer statistics. CA Cancer J Clin 54: 8-29, 2004.

2. American Cancer Society: Cancer facts and figures. American Cancer Society, Washington, DC, pp1-39, 2000.

3. Winawer SJ: A quarter century of colorectal cancer screening: progress and prospects. J Clin Oncol 19 (Suppl. 18): S6-S12, 2001.

4. Ransohoff DF and Sandler RS: Clinical practice. Screening for colorectal cancer. N Engl J Med 346: 40-44, 2002.

5. Thomas FI, David FR, Steven HI, Barry AT and Michael ER: Fecal DNA versus fecal occult blood for colorectal-cancer screening in an average risk population. N Engl J Med 351: 2704-2714, 2004.

6. Lieberman DA and Weiss DG: One-time screening for colorectal cancer with combined fecal occult-blood testing and examination of the distal colon. N Engl J Med 345: 355-360, 2001.

7. Fletcher RH: Carcinoembryonic antigen. Ann Intern Med 104: 66-73, 1986.

8. Shimada H, Ochiai T, Nomura F and Japan p53 Antibody Research Group: Titration of serum p53 antibodies in 1085 patients with various types of malignant tumors: a multiinstitutional analysis by the Japan p53 Antibody Research Group. Cancer 97: 682-689, 2003.

9. Levine A, Momand J and Finlay C: The p53 tumor suppressor gene. Nature 351: 453-455, 1991.

10. Crawford LV, Pim DC and Bulbrook RD: Detection of antibodies against the cellular protein p53 in sera from patients with breast cancer. Int J Cancer 30: 403-408, 1982.

11. Castaldi F, Marino M, Belluco C, De Marchi F, Mammano E, Nitti D, Lise M and Fassina G: Detection of circulating CEA-IgM complexes in early stage colorectal cancer. Int J Biol Markers 20: 204-208, 2005.

12. Christian F, Friedel K, Peter K, Suse H, Wolfram J and Jochen RK: CEA-containing immune complexes in sera of patients with colorectal and breast cancer: analysis of complexed immunoglobulin classes. Cancer Immunol Immunother 26: 180-184, 1988.

13. Palombo G, Verdoiva A and Gassina G: Affinity purification of immunoglobulin $\mathrm{M}$ using a novel synthetic ligand. J Chromatogr B 715: 137-145, 1998.

14. Dalgaard P: Introductory statistics with R. Springer-Verlag, New York Inc., 2002

15. Yahui S, Jing S, Huachong M, et al: Diagnosis of gastric cancer using decision tree classification of mass spectra data. Cancer Sci 98: 37-43, 2007.

16. Kojima T, Yoshikawa K, Matsui T, Kodera Y and Kojima H: Detection of elevated proteins in peritoneal dissemination of gastric cancer by analyzing mass spectra data of serum proteins. J Surg Sci (In press).

17. Gorelik E, Landsittel DP, Marrangoni AM, Mondugno F, Velikokhatnaya L, Winans MT, Bigbee WL, Herberman RB and Lokshin AE: Multiplexed immunobead-based cytokine profiling for early detection of ovarian cancer. Cancer Epidemiol Biomarkers Prev 14: 981-987, 2005. 